Study of Chemical Changes in Uranium Oxyfluoride Particles Progress Report March - October 2009

R. Kips, M. Kristo, I. Hutcheon

November 25, 2009 
This document was prepared as an account of work sponsored by an agency of the United States government. Neither the United States government nor Lawrence Livermore National Security, LLC, nor any of their employees makes any warranty, expressed or implied, or assumes any legal liability or responsibility for the accuracy, completeness, or usefulness of any information, apparatus, product, or process disclosed, or represents that its use would not infringe privately owned rights. Reference herein to any specific commercial product, process, or service by trade name, trademark, manufacturer, or otherwise does not necessarily constitute or imply its endorsement, recommendation, or favoring by the United States government or Lawrence Livermore National Security, LLC. The views and opinions of authors expressed herein do not necessarily state or reflect those of the United States government or Lawrence Livermore National Security, LLC, and shall not be used for advertising or product endorsement purposes.

This work performed under the auspices of the U.S. Department of Energy by Lawrence Livermore National Laboratory under Contract DE-AC52-07NA27344. 


\section{Study of Chemical Changes in Uranium Oxyfluoride Particles Progress report March - October 2009 \\ LLNL-TR-420742}

Ruth S. Kips, Michael J. Kristo, Ian D. Hutcheon

Lawrence Livermore National Laboratory, Chemical Sciences Division

7000 East Avenue, Livermore, CA 94550

\section{Project definition}

Nuclear forensics relies on the analysis of certain sample characteristics to determine the origin and history of a nuclear material. In the specific case of uranium enrichment facilities, it is the release of trace amounts of uranium hexafluoride $\left(\mathrm{UF}_{6}\right)$ gas - used for the enrichment of uranium - that leaves a processcharacteristic fingerprint. When $\mathrm{UF}_{6}$ gas interacts with atmospheric moisture, uranium oxyfluoride particles or particle agglomerates are formed with sizes ranging from several microns down to a few tens of nanometers. These particles are routinely collected by safeguards organizations, such as the International Atomic Energy Agency (IAEA), allowing them to verify whether a facility is compliant with its declarations.

Spectrometric analysis of uranium particles from $\mathrm{UF}_{6}$ hydrolysis has revealed the presence of both particles that contain fluorine, and particles that do not. It is therefore assumed that uranium oxyfluoride is unstable, and decomposes to form uranium oxide. Understanding the rate of fluorine loss in uranium oxyfluoride particles, and the parameters that control it, may therefore contribute to placing boundaries on the particle's exposure time in the environment.

Expressly for the purpose of this study, we prepared a set of uranium oxyfluoride particles at the Institute for Reference Materials and Measurements (EU-JRC-IRMM) from a static release of $U_{F}$ in a humid atmosphere. The majority of the samples was stored in controlled temperature, humidity and lighting conditions. Single particles were characterized by a suite of micro-analytical techniques, including NanoSIMS, micro-Raman spectrometry (MRS), scanning (SEM) and transmission (TEM) electron microscopy, energy-dispersive X-ray spectrometry (EDX) and focused ion beam (FIB). The small particle size was found to be the main analytical challenge. The relative amount of fluorine, as well as the particle chemical composition and morphology were determined at different stages in the ageing process, and immediately after preparation. This report summarizes our most recent findings for each of the analytical techniques listed above, and provides an outlook on what remains to be resolved. Additional spectroscopic and mass spectrometric measurements were carried out at Pacific Northwest National Laboratory, but are not included in this summary.

This work has been performed under the auspices of the U.S. Department of Energy through a joint program between Lawrence Livermore National Laboratory (under contract DE-AC52-07NA27344) and the Pacific Northwest National Laboratory (under contract DE-AC05-76RL01830), and under the auspices of the European Commission, DG Joint Research Centre under Action Sheet 36. 


\section{Summary Activities March - October 2009}

\section{Sample storage and ageing}

A total of 174 particle samples (graphite, zinc selenide and sapphire substrates) were prepared from the controlled hydrolysis of $\mathrm{UF}_{6}\left({ }^{235} \mathrm{U}=0.704 \%\right)$ in January 2009, at IRMM in Belgium. All samples were shipped to LLNL in argon-filled containers for either:

- storage in a sealed argon atmosphere

- $\quad$ storage in one of 4 environmental chambers

- $\quad$ immediate analysis by NanoSIMS at LLNL to provide a starting point $(\mathrm{t}=0)$ measurement

- further distribution to PNNL for CLIFS, Raman and SIMS analysis

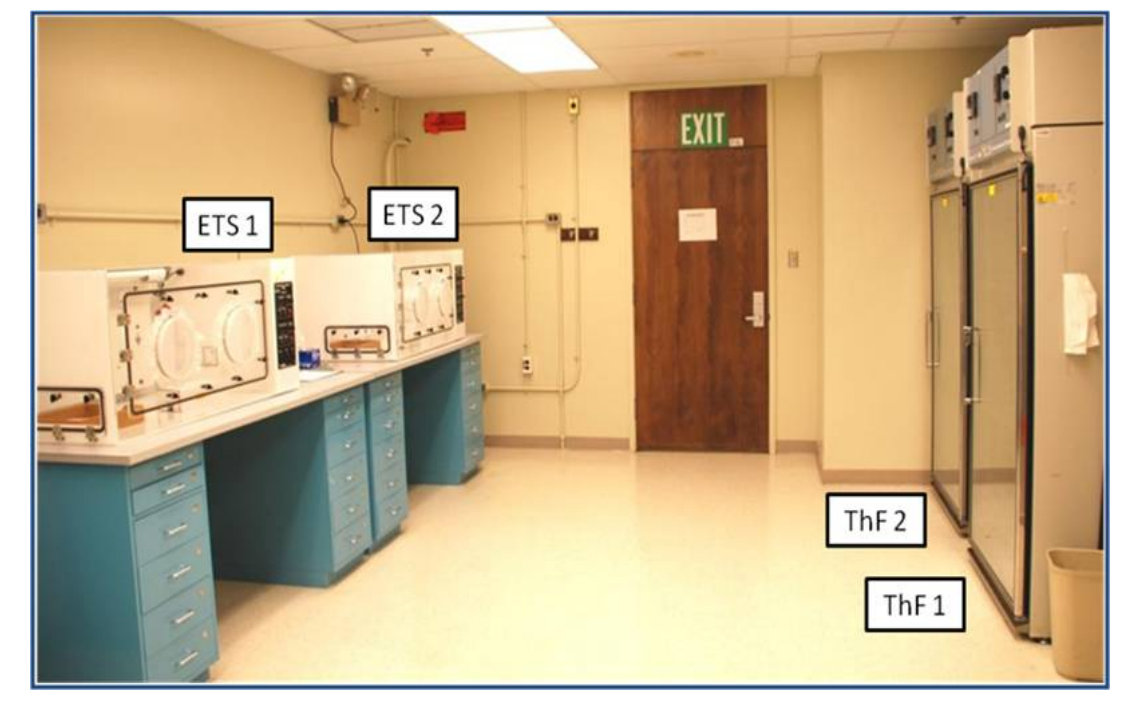

\begin{tabular}{|l|l|l|l|l|}
\hline Chamber & ETS1 & ETS2 & ThF1 & ThF2 \\
\hline Temperature & $24 \pm 1{ }^{\circ} \mathrm{C}$ & $40 \pm 2{ }^{\circ} \mathrm{C}$ & $25.5 \pm 0.3{ }^{\circ} \mathrm{C}$ & $40.6 \pm 0.1{ }^{\circ} \mathrm{C}$ \\
\hline Rel. humidity & $<15 \%$ & $<15 \%$ & $76 \pm 0.4 \%$ & $77 \pm 0.4 \%$ \\
\hline Light & $\begin{array}{l}\text { Daylight } \\
\text { simulated/Dark }\end{array}$ & Diffuse/Dark & Diffuse & Diffuse \\
\hline
\end{tabular}

Fig 1 \& Table 1: Environmental chambers and their conditions for storage of $\mathrm{UO}_{2} \mathrm{~F}_{2}$ particle samples at LLNL

The sample storage time in these chambers varied between a few days up until 10 months, since their production at IRMM in January. Twenty samples (graphite planchets + sapphire) are currently still ageing in the chambers at LLNL. 


\section{Mass spectrometry at the nano-scale: NanoSIMS}

The Cameca NanoSIMS 50 secondary ion mass spectrometer at LLNL is able to measure the elemental composition of individual uranium oxyfluoride particles, due to its nanometer-scale spatial resolution and high transmission. NanoSIMS is a destructive technique in which a beam of high energy primary ions is rastered onto the sample, producing secondary ions that are detected by a double-focusing mass spectrometer (Fig. 2). The sputtering process is not limited to the surface layer, but consists of implantation of the primary ions into the sample and the removal of surface atoms through a so-called collision cascade.

A primary beam of $\mathrm{O}^{-}$ions is used to enhance the production of electropositive secondary ions, such as $\mathrm{U}^{+}$, whereas bombardment with $\mathrm{Cs}^{+}$ions enhances the generation of electronegative secondary ions, including $\mathrm{F}^{-}$. The spatial resolution is better for $\mathrm{Cs}^{+}$primary ion bombardment (down to $100 \mathrm{~nm}$ ), and electron images can be collected in addition to a set of ion images for this type of primary ions.
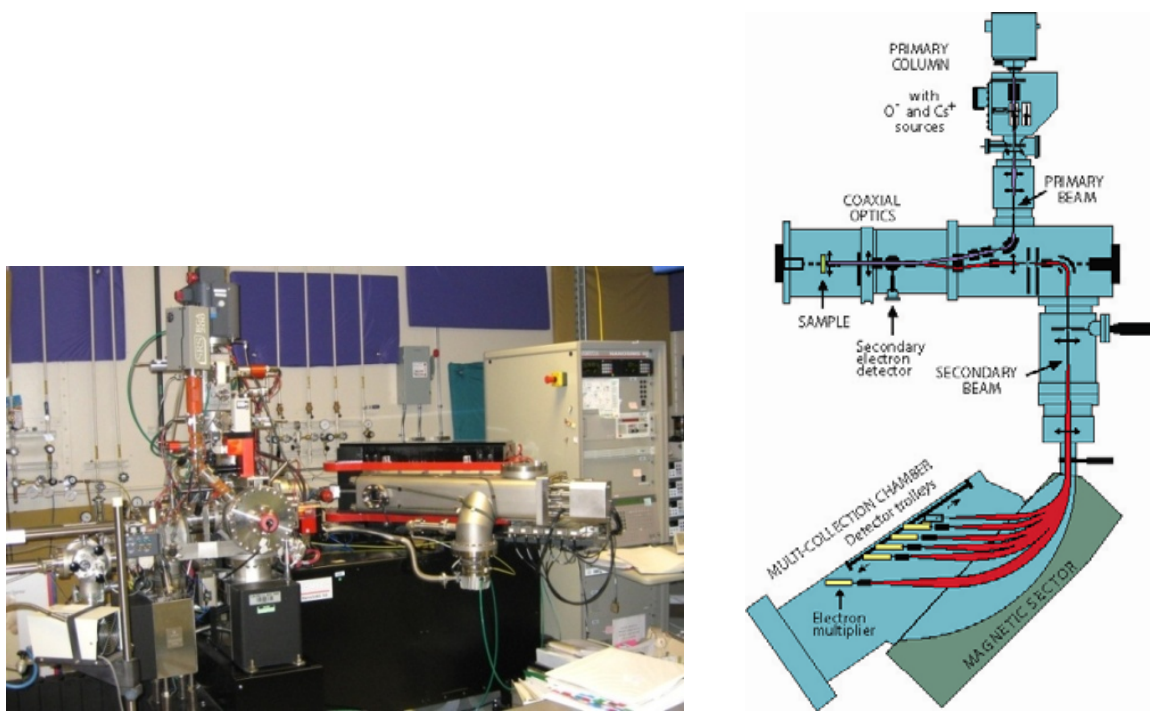

Fig 2. Picture and diagram of the Cameca NanoSIMS 50 at LLNL

Figure 3 shows the electron image and the fluorine and oxygen secondary ion images of a uranium oxyfluoride particle - or possibly particle agglomerate - generated by rastering a $\mathrm{Cs}^{+}$primary ion beam across a $6 \mu \mathrm{m} \times 6 \mu \mathrm{m}$ area. These ion images are a visual representation of the fluorine and oxygen distribution in the particle, and are part of a sequence of images recorded during sputtering. The images in Figure 3 seem to indicate that the lower left side has a higher fluorine-to-oxygen ratio than the rest of the particle, suggesting that fluorine is not homogeneously distributed throughout the particle. Although this could in fact be the case, there are a number of considerations that need to be taken into account when interpreting the ion images of these submicron-sized particles. The electron image on the left shows a black spot in the center of the particle, indicating that charge is building up from sputtering the particle with an ion beam. This may affect the relative ion yield. Secondly, the secondary ion yield is dependent on the angle of incidence of the beam, and therefore particle topography could introduce artifacts. We 
should also keep in mind that the beam size is in the order of $100 \mathrm{~nm}-200 \mathrm{~nm}$. This means that the area from which the secondary ions are generated is substantially larger than the pixel size.
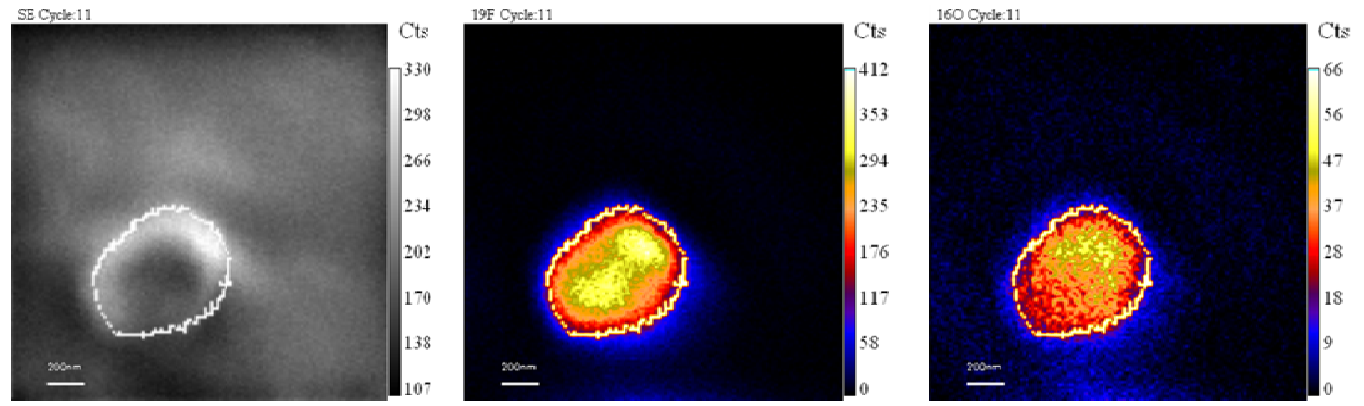

Fig 3: Secondary electron image (left) and $\mathrm{F}^{-}$(middle) and $\mathrm{O}^{-}$(right) secondary ion image of a uranium oxyfluoride particle or particle agglomerate generated by the NanoSIMS 50 while sputtering a $6 \mu \mathrm{m} \times 6 \mu \mathrm{m}$ area with a $\mathrm{Cs}^{+}$primary ion beam. The white and yellow pixels in the ion images represent the most intense secondary ion intensity. The white/yellow line was added by image processing software to define the region of interest.

By selecting a region of interest that overlaps with the particle area (white/yellow line), we are able to plot the variation of the total counts of fluorine and oxygen ions relative to the time of sputtering. This plot is referred to as a depth profile. Examples are shown in Figure 4 and Figure 5. The small mass difference between fluorine and oxygen allowed for the simultaneous collection of the $\mathrm{F}^{-}$and $\mathrm{O}^{-}$ secondary ions in two different secondary electron multiplier detectors (multi-collection). Uranium secondary ions were not included in the analysis, as the count rate was too low. For the particle shown in Figure 4, which was stored in dry air at $25^{\circ} \mathrm{C}$ for 6 months, the fluorine and oxygen ions were highly correlated and showed a similar behavior throughout the analysis. The average $\mathrm{F}^{-} / \mathrm{O}^{-}$ratio calculated from this depth profile was $5.68 \pm 0.01$. For the other particles analyzed on this sample the $\mathrm{F}^{-} / \mathrm{O}^{-}$ratio varied between 2 and 10. In comparison, the $\mathrm{F}^{-} / \mathrm{O}^{-}$ratio for particle samples stored in high humidity conditions (76-77\%) was typically 3 orders of magnitude lower.

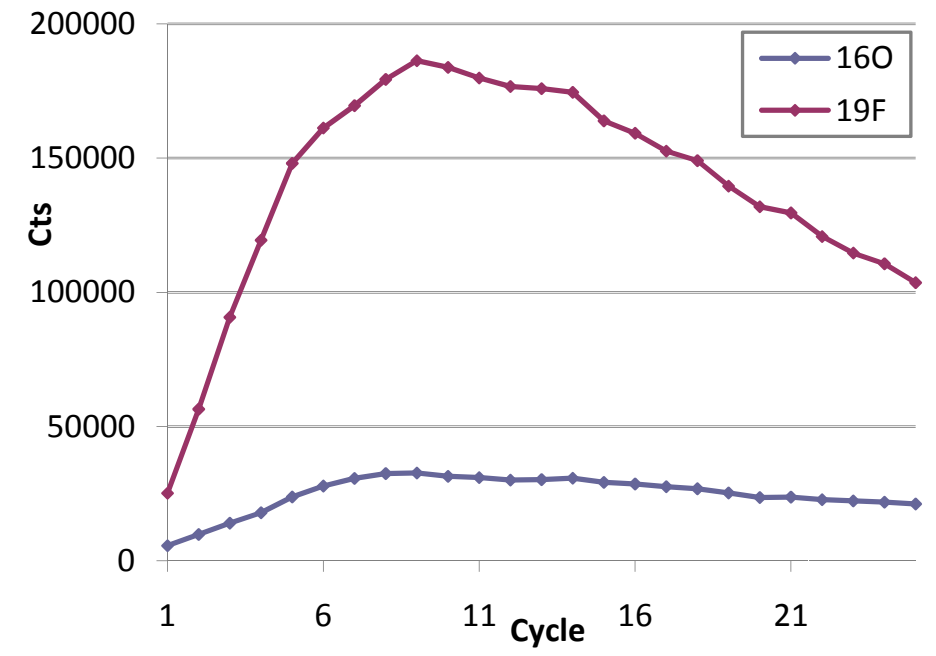

Fig 4: Depth profile showing the secondary fluorine and oxygen ion intensity variations as a function of cycle number in a single uranium oxyfluoride particle during $\mathrm{Cs}^{+}$sputtering 


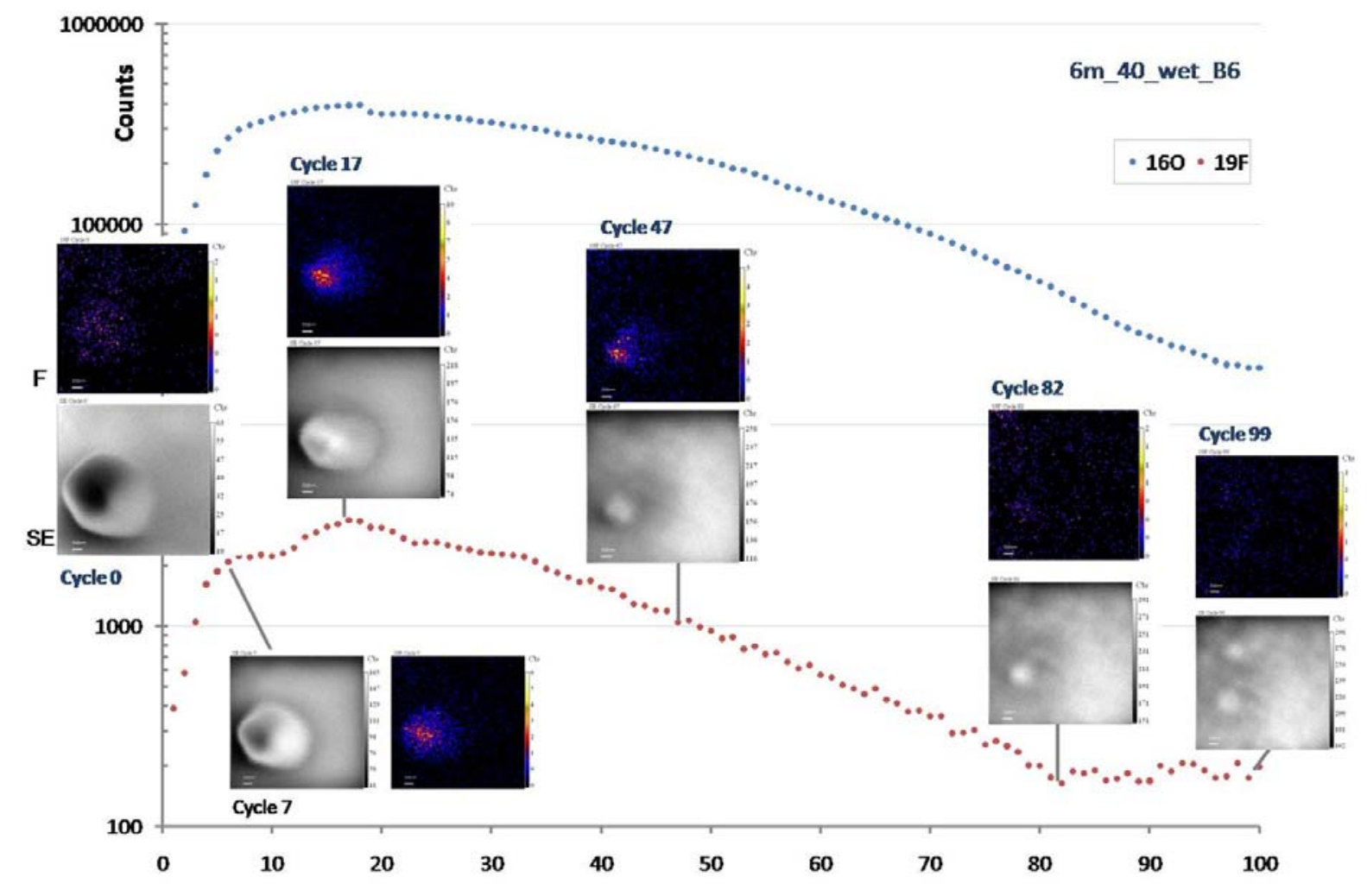

Fig 5: Depth profile showing the secondary fluorine ion intensity as a function of cycle number ( $\log$ scale) Fluorine ion images and their corresponding electron images are shown for the different stages in the sputtering process The electron image for cycle 0 and 7 show signs of charging (black area)

In order to quantify the amount of fluorine in a single particle however, the fluorine secondary ion intensity should ideally be compared to the intensity of an ion characteristic of the uranium oxide matrix, that remains relatively constant throughout the analysis. By switching the primary ion bombardment from $\mathrm{Cs}^{+}$to $\mathrm{O}^{-}$, the secondary ion yield for the uranium ions was greatly increased, and the $\mathrm{U}^{+}, \mathrm{UO}^{+}$and $\mathrm{UF}^{+}$ and $\mathrm{UO}_{2}{ }^{+}$secondary ions were included in the analysis. The mass table used for the measurement set up and the resulting depth profile are shown in Table 2 and Figure 6 respectively.

\begin{tabular}{|c|c|c|c|c|}
\hline EM 1 & EM 2 & EM 3 & EM4 & EM 5 \\
\hline${ }^{12} \mathrm{C}^{+}$ & ${ }^{16} \mathrm{O}^{+}$ & ${ }^{19} \mathrm{~F}^{+}$ & & \\
\hline & & & & ${ }^{238} \mathrm{U}^{+}$ \\
\hline & & & ${ }^{238} \mathrm{U}^{16} \mathrm{O}^{+}$ \\
\hline & & & ${ }^{238} \mathrm{U}^{19} \mathrm{~F}^{+}$ \\
\hline & & & & ${ }^{238} \mathrm{U}^{16} \mathrm{O}_{2}^{+}$ \\
\hline
\end{tabular}

Table 2. Analysis set up showing the different secondary ions collected in 4 different electron multiplier detectors. The large mass difference between fluorine and uranium required changes in the magnetic field for the uranium masses (peak jumping) 


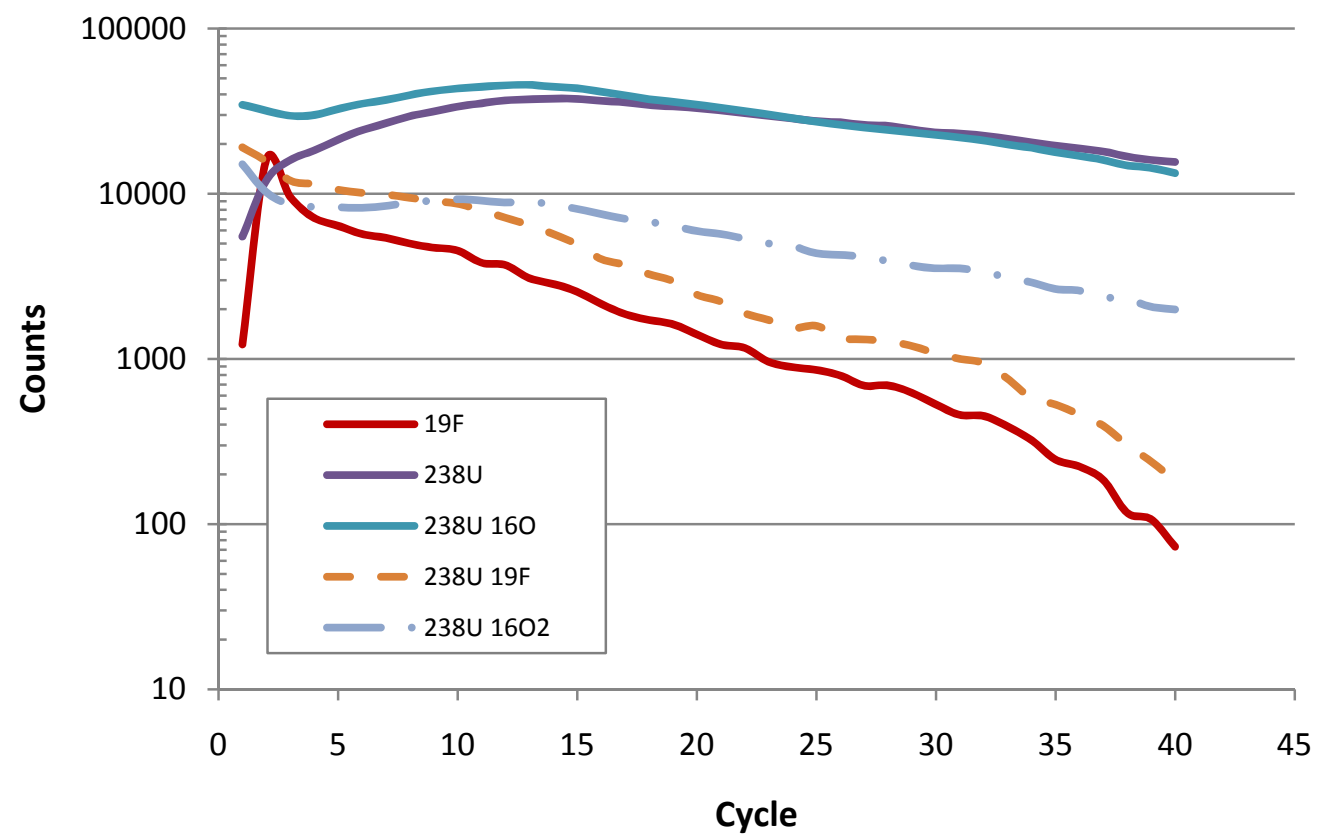

Fig 6: Depth profile generated by $\mathrm{O}^{-}$primary ion bombardment of a uranium oxyfluoride particle stored in dry air for 3 months

The depth profile in Figure 6 shows a rapid increase in the $\mathrm{F}^{+}$count rate to around $5000 \mathrm{cps}$ during the first few cycles, after which it steadily decreased as sputtering progressed. This initial increase was not observed for all particle measurements, in which case the fluorine showed a steady decrease from the start of the analysis. The $\mathrm{U}^{+}$ions on the other hand, required sufficient implantation of $\mathrm{O}^{-}$primary ions before these ions reached their maximum intensity. In the example in Figure 6 this occurs around cycle 11.

The $\mathrm{F}^{+} / \mathrm{U}^{+}$ratio was obtained from the total counts for the total duration of the analysis, integrated over the entire rastered area. These values were used to compare the relative amount of fluorine between particles stored in different environmental conditions and those measured immediately after preparation. Figure 7 shows an overview of the $\mathrm{F}^{+} / \mathrm{U}^{+}$ratio of the aged and fresh uranium oxyfluoride samples that have been analyzed so far. The error bars represent the standard error of the mean. The first 2 samples (fresh 1, fresh 2) were analyzed 2-3 weeks after preparation at IRMM and were stored in an argon atmosphere before analysis. These samples are therefore considered to be 'fresh', and their $\mathrm{F}^{+} / \mathrm{U}^{+}$ratios represent the initial relative amount of fluorine before any ageing occurs $\left(\mathrm{t}=0\right.$ measurement). The $\mathrm{F}^{+} / \mathrm{U}^{+}$ ratios for these fresh samples were $0.14 \pm 0.05$ and $0.09 \pm 0.01$ respectively. 


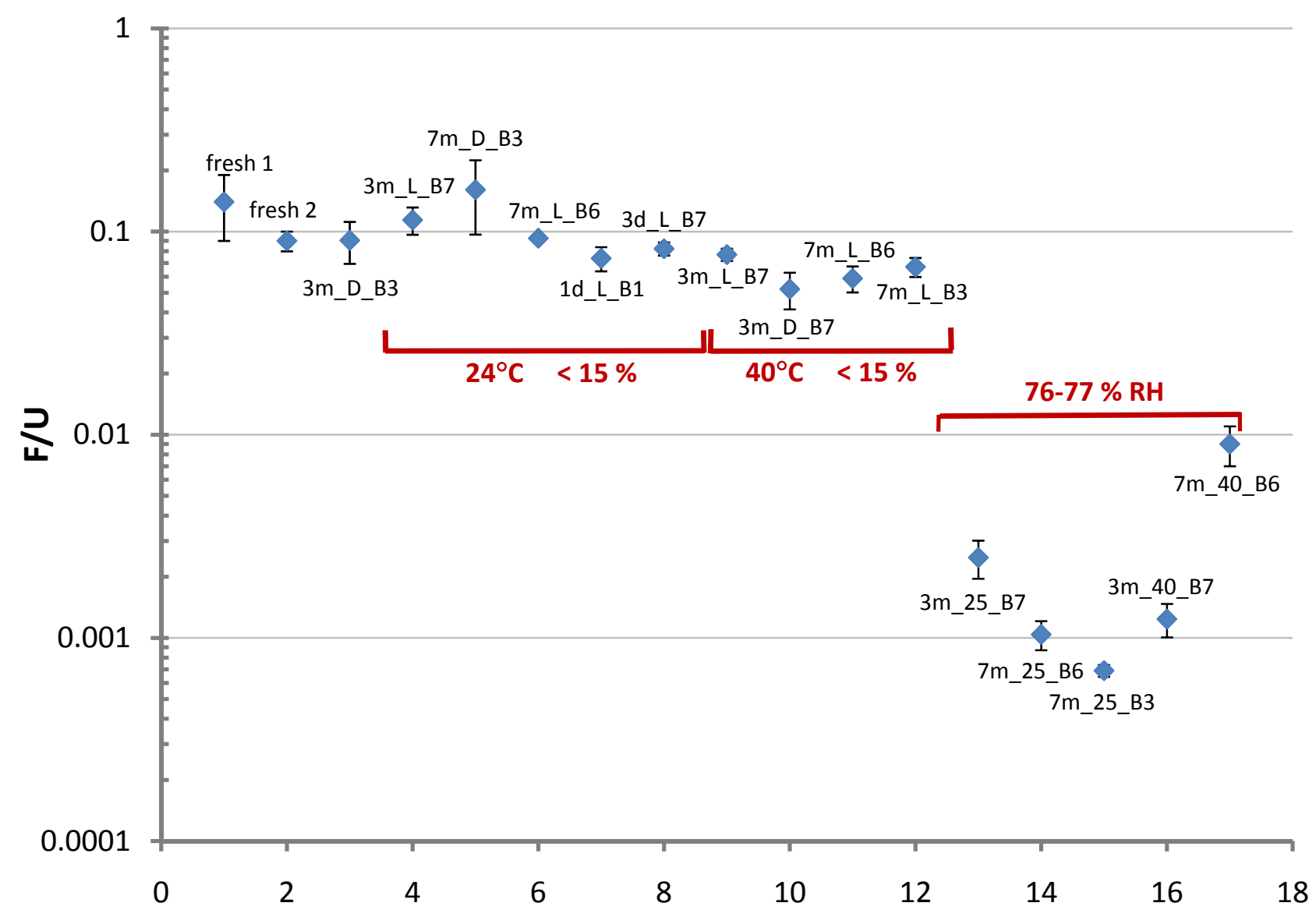

Fig 7: Overview of the $\mathrm{F}^{+} / \mathrm{U}^{+}$ratios of 17 uranium oxyfluoride particle samples measured by NanoSIMS using $\mathrm{O}^{-}$primary ion bombardment

The other samples were stored in the environmental chambers at LLNL under different humidity, temperature and lighting conditions, and this for various amounts of time. The sample labels indicate the time in the environmental chamber $(7 \mathrm{~m}=7$ months, $3 \mathrm{~m}=3$ months, $1 \mathrm{~d}=1$ day, etc), while the letter $\mathrm{L}$ or D denotes whether they were exposed to diffuse or sunlight simulated light (L), or stored in the dark (D), and finally the $\mathrm{B}$ number at the end of the labels represents the particle production batch number. The plotted ratio is the average of 4-7 particles for each of the samples. The analysis was stopped after the intensity of the $\mathrm{F}^{+}$ions was reduced to background.

The $\mathrm{F}^{+} / \mathrm{U}^{+}$ratio for the samples stored in low relative humidity air showed no significant decrease compared to the freshly-prepared samples, indicating that little or no ageing occurred after 7 months of storage under these conditions. In addition, single-factor ANOVA analysis $(\alpha=0.05)$ concluded that the $\mathrm{F}^{+} / \mathrm{U}^{+}$variance associated with the different temperature and lighting conditions in these dry air samples did not exceed the variance expected from random error.

The $\mathrm{F}^{+} / \mathrm{U}^{+}$ratio for the samples stored in high humidity air $(76-77 \%)$ on the other hand showed larger differences between samples. This variation, as well as the variation between particles from the same sample (as represented by the error bars), was attributed to changes in particle composition and 
morphology as result of the exposure to moisture. Despite this variability, the intensity of the fluorine ions and the resulting $\mathrm{F}^{+} / \mathrm{U}^{+}$ratios varied between one and two orders of magnitude below the values of those samples kept in a dry atmosphere. The count rates for fluorine started off at around 10-50 cps, compared to several hundred cps for the samples stored in dry air, and were typically reduced to only a few counts per second after less than 10 cycles $(<30$ min of sputtering $)$.

\section{Sample prep and post-analysis: Scanning Electron Microscopy (SEM)}

Although NanoSIMS is a very powerful technique for the analysis of single particles, sample characterization using scanning electron microscopy (SEM) remains indispensable, both before and after NanoSIMS analysis. Images and compositional information is obtained by rastering a highly-focused electron beam across the sample. Figure 8 is an example of an SEM image of a uranium oxyfluoride particle sample (3/8" graphite substrate) that was analyzed by NanoSIMS.

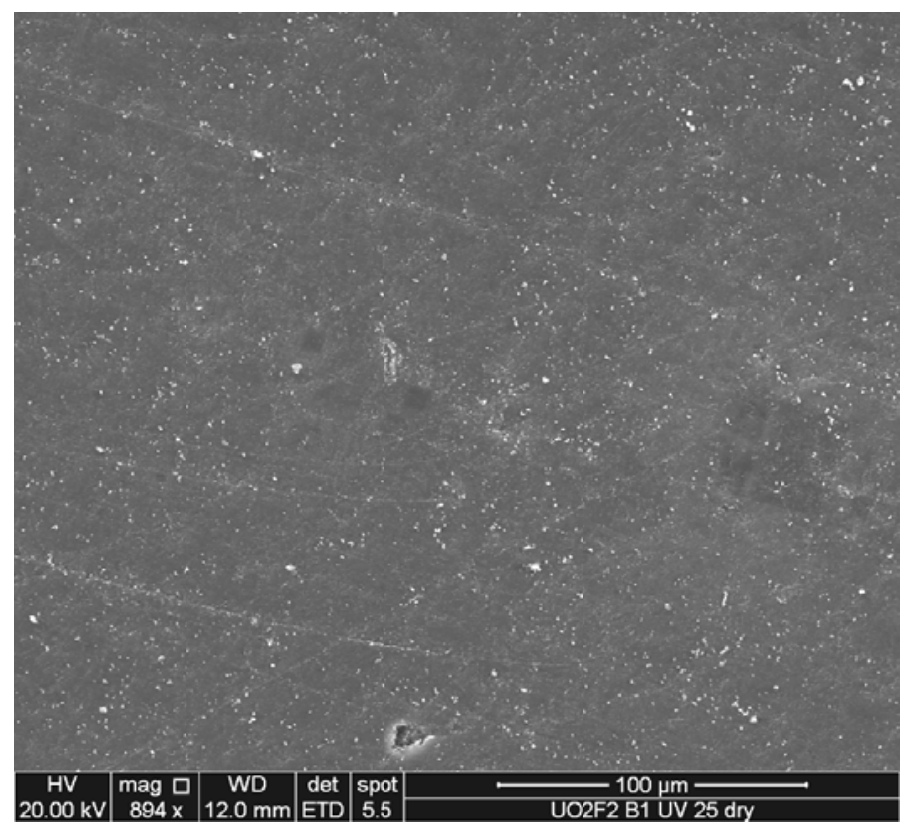

Fig 8: SEM image of uranium oxyfluoride particles (white dots) on a graphite substrate. The center of the image shows a series of NanoSIMS craters (square dark areas)

This image shows a series of $\sim 6 \mu \mathrm{m} \times 6 \mu \mathrm{m}$ craters from sputtering the sample with the NanoSIMS primary ion beam, as well as larger craters produced during ion beam centering and alignment. The rough surface topography of the graphite substrate made the relocation of these small and shallow NanoSIMS craters very difficult. Nevertheless, relocating these NanoSIMS craters is important to determine what is left of the particle that was analyzed. Figure 9 shows a NanoSIMS crater with in the center a particle that is partially eroded. 

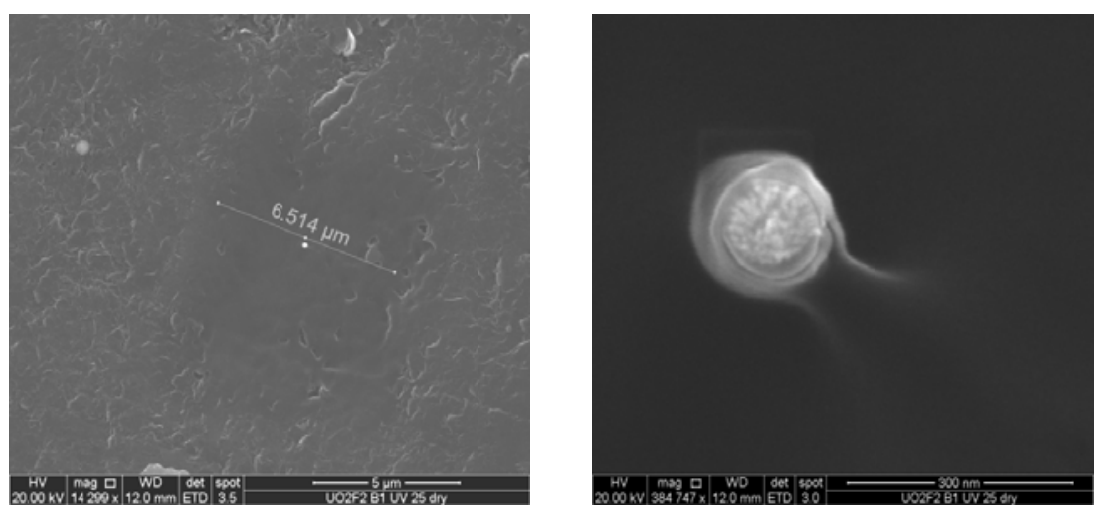

Fig 9: SEM images of a NanoSIMS crater (left) with in the center a very small particle that shows clear signs of sputtering (right)

Although this particle was sputtered by NanoSIMS, the energy-dispersive X-ray spectrum (EDX) still detected fluorine in this very small particle (Figure 10). As described in the previous section, the NanoSIMS sputtering using $\mathrm{O}^{-}$primary bombardment is stopped when the intensity of the fluorine secondary ions reaches background levels. Re-deposition of sputtered atoms may however extend the fluorine ion intensity until after the particle has been eroded. In addition, the size and morphology of the particle could also affect the sputtering process. Understanding how the particle is being sputtered by the primary ion, and how morphology affects the sputtering process and secondary ion yield is crucial to the interpretation of the depth profiles obtained by NanoSIMS. In the next section, it is explained how sample manipulation using a focused ion beam (FIB) can make the particle relocation process more efficient.

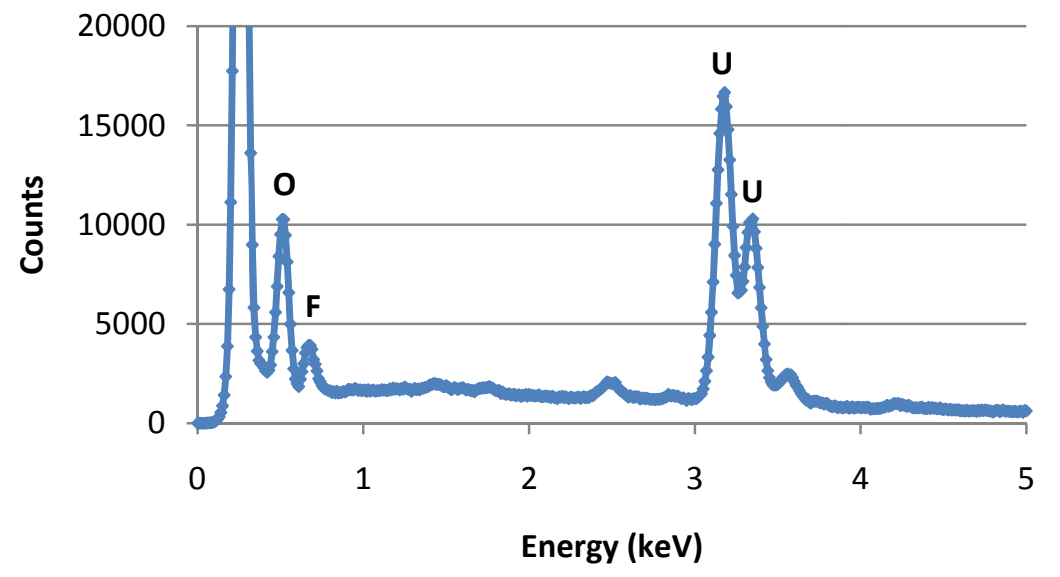

Fig 10: Energy-dispersive $\mathrm{X}$-ray spectrum of the particle in Figure 8 showing U, F, and $\mathrm{O}$ as the main constituents. The peak on the far left is the $\mathrm{C}$ peak produced by the graphite substrate

The SEM at LLNL was also used to evaluate changes in particle morphology after storage in the environmental chambers for various amounts of time. The SEM images in Figure 11 show particle agglomerates after respectively one week and one month exposure to $40 \%$ relative humidity at $30{ }^{\circ} \mathrm{C}$. The individual particles that comprise the particle agglomerate in the left image are still clearly defined after one week of storage, whereas the particles of the agglomerate on the right (one month of storage) have partially fused to form a larger entity. The individual particles that are part of this entity can still be identified however. 

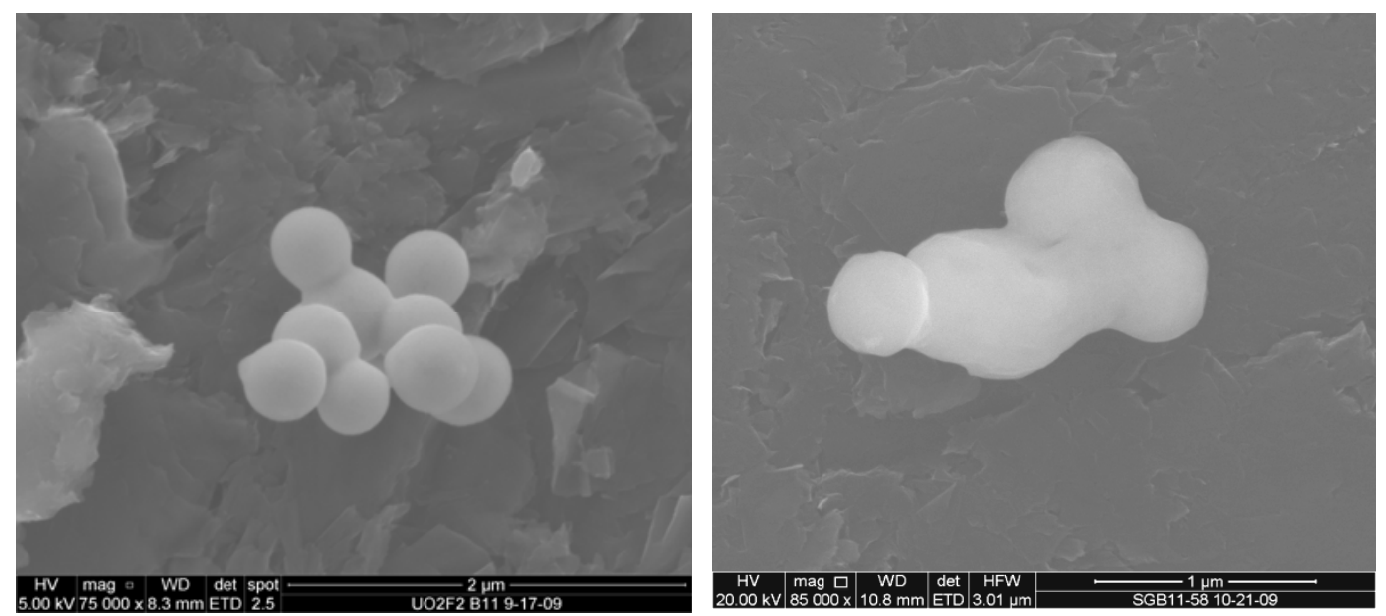

Fig 11: SEM images of particle agglomerates after exposure to $40 \%$ rel. humidity $-30{ }^{\circ} \mathrm{C}$ for 1 week (left) and 1 month (right)

\section{Micro-surgery with the Focused Ion Beam (FIB)}

In order to facilitate particle relocation, a set of samples was manipulated by a focused ion beam (FIB) prior to NanoSIMS analysis. The FIB deposited 3 distinctive platinum marks on each of these samples, so that the coordinates of the particles analyzed by the NanoSIMS can be transferred to the SEM for postanalysis imaging. For one sample, stored in argon since its preparation at IRMM, eight individual uranium oxyfluoride particles were selected by SEM imaging. These particles were selected based on their morphology and size. A platinum mark shaped as cross was deposited next to these particles, so that they could be identified in the NanoSIMS and the SEM (Figure 12). For each of these eight particles, the NanoSIMS sputtering process will be stopped at different time intervals. Post-analysis SEM imaging of these particles will allow us to correlate the secondary ion yield to the stage of sputtering and the particle morphology. This is why we selected single particles, not agglomerates, with a similar morphology and size. 

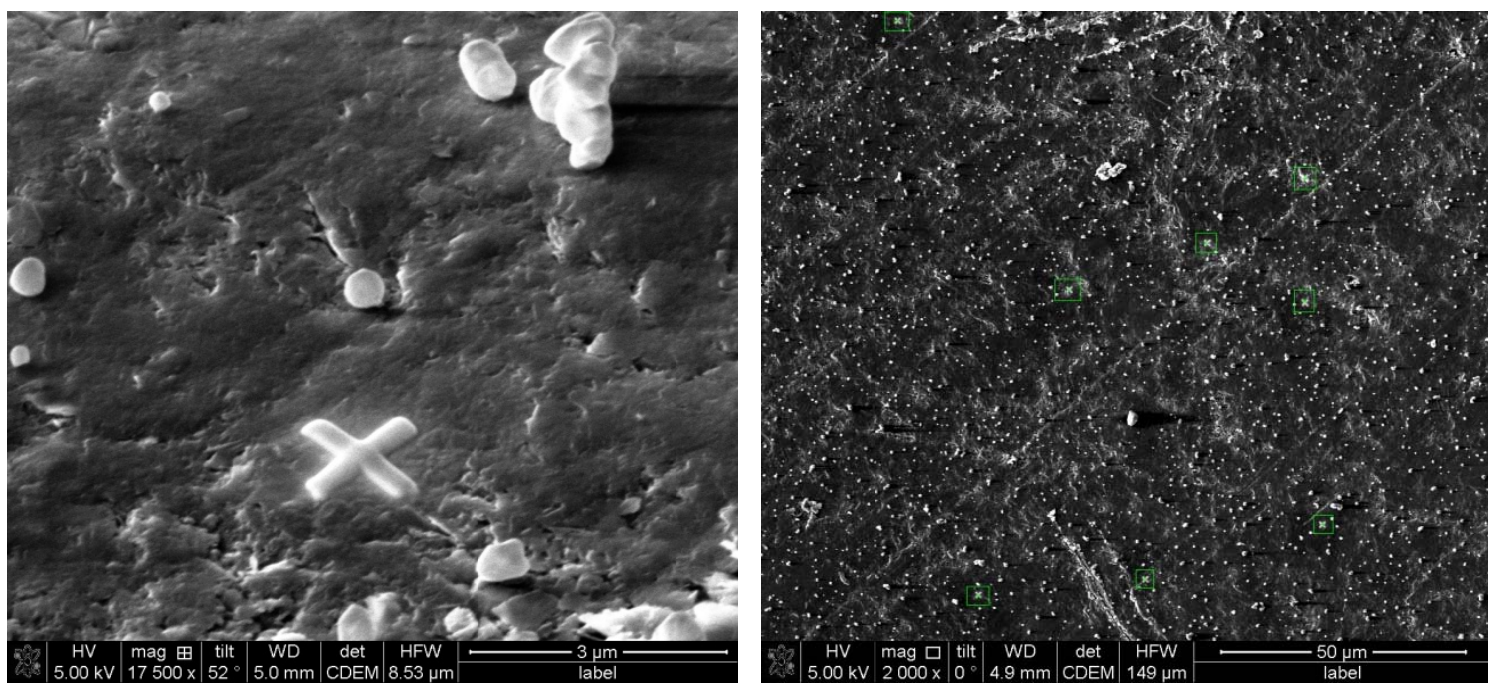

Fig 12: SEM image of a uranium oxyfluoride particle marked by a cross-shaped Pt deposit (left) and an overview SEM images of the 8 particles selected for Pt marking on this sample

Previous SEM imaging had revealed a rather porous structure for particles that had been sputtered by NanoSIMS (Figure 13) and this topography could have either been revealed or introduced by NanoSIMS sputtering. With a technique called 'slice \& view' we were able to look inside a Pt-coated particle by milling the particle from an angle with a primary ion beam, followed by SEM imaging of the crosssections at regular time intervals. The SEM image in Figure 14 is an example of such a cross-section and shows the presence of small voids in the center and at the surface of the particle. Although the ion milling process may also introduce artifacts, it is assumed that these voids are real. Because of their small size however, we cannot determine their composition with the analytical techniques that are currently available.
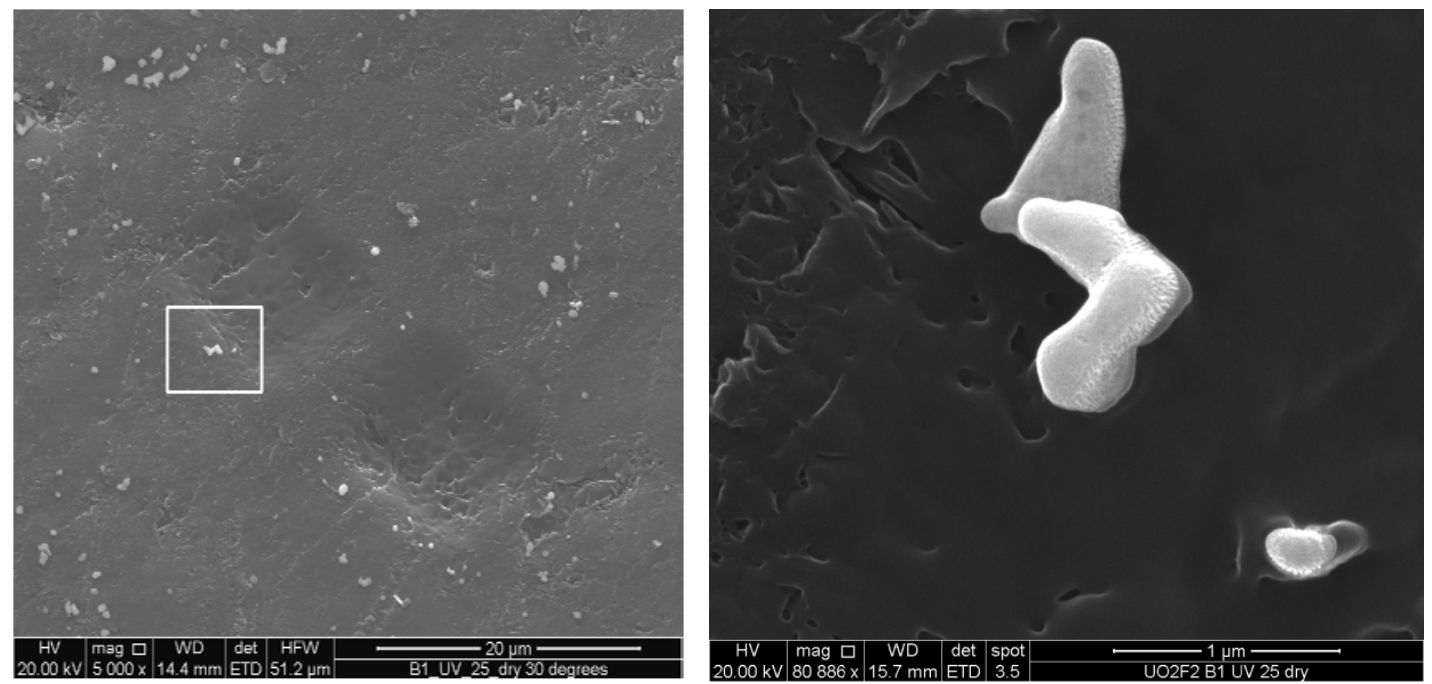

Fig 13: SEM images of a uranium oxyfluoride particle agglomerate at the edge of a NanoSIMS crater (left) showing a rather porous structure after NanoSIMS sputtering (right) 


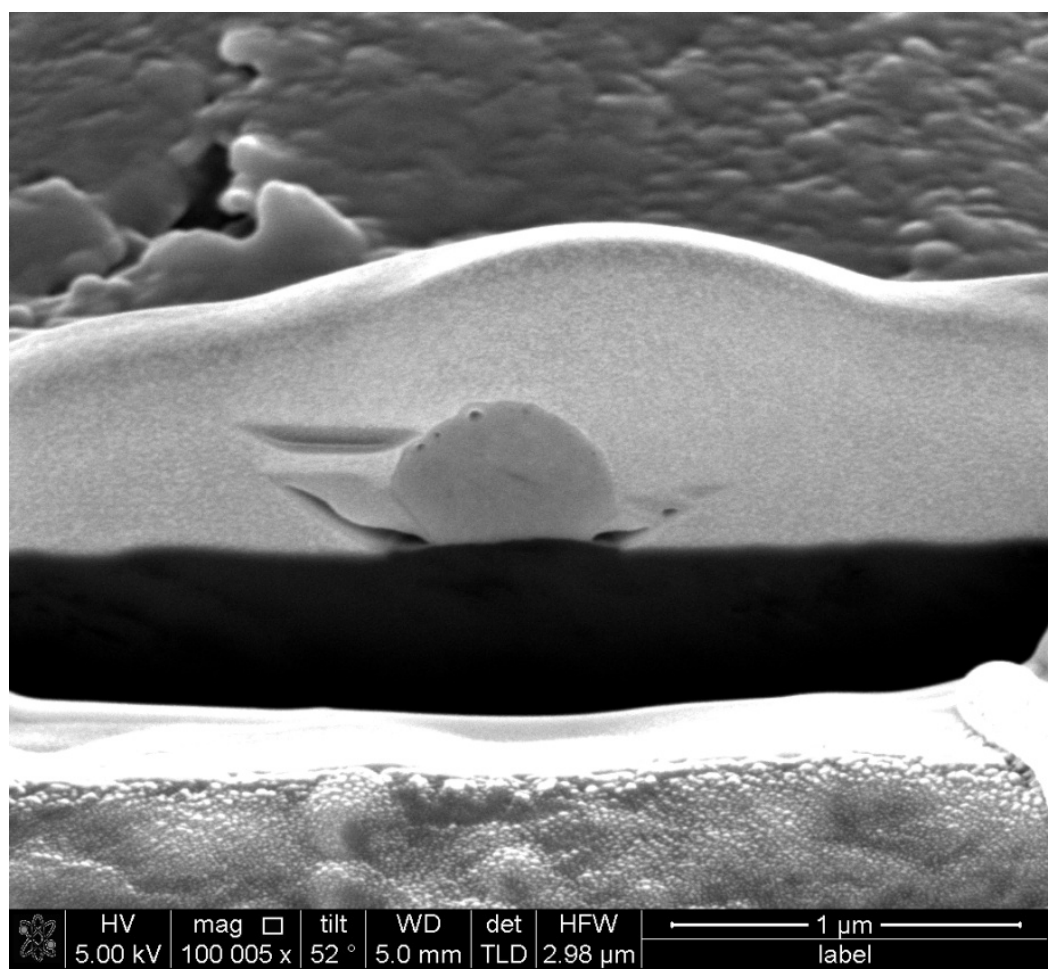

Fig 14: SEM images of a cross-section of a single uranium oxyfluoride particle coated with $\mathrm{Pt}$ showing several voids at the surface and in the center of the particle

\section{Transmission Electron Microscopy (TEM) - imaging the fluorine distribution}

These FIB measurements demonstrated how investigating the particle's (inner) structure can complement the elemental information obtained by NanoSIMS. The NanoSIMS depth profile in Figure 6 showed an initial increase in the fluorine secondary ion intensity, after which it steadily decreased to background values. If we think of the particle as a uranium oxide sphere, and we assume that the fluorine is homogeneously distributed, we would expect the fluorine intensity to gradually decrease as the particle is being eroded by the primary ion beam. On the other hand, if we assume that the fluorine is concentrated in the particle's surface layer, we would expect to see an increase at the very start of the analysis when the surface layer is being sputtered, followed by another increase when we get to the other side of the particle. The generation of secondary ions is a very complex process however, and so without additional knowledge of how the fluorine is distributed throughout the particle, we cannot make any statements about what caused this initial increase in the secondary fluorine ion intensity. 

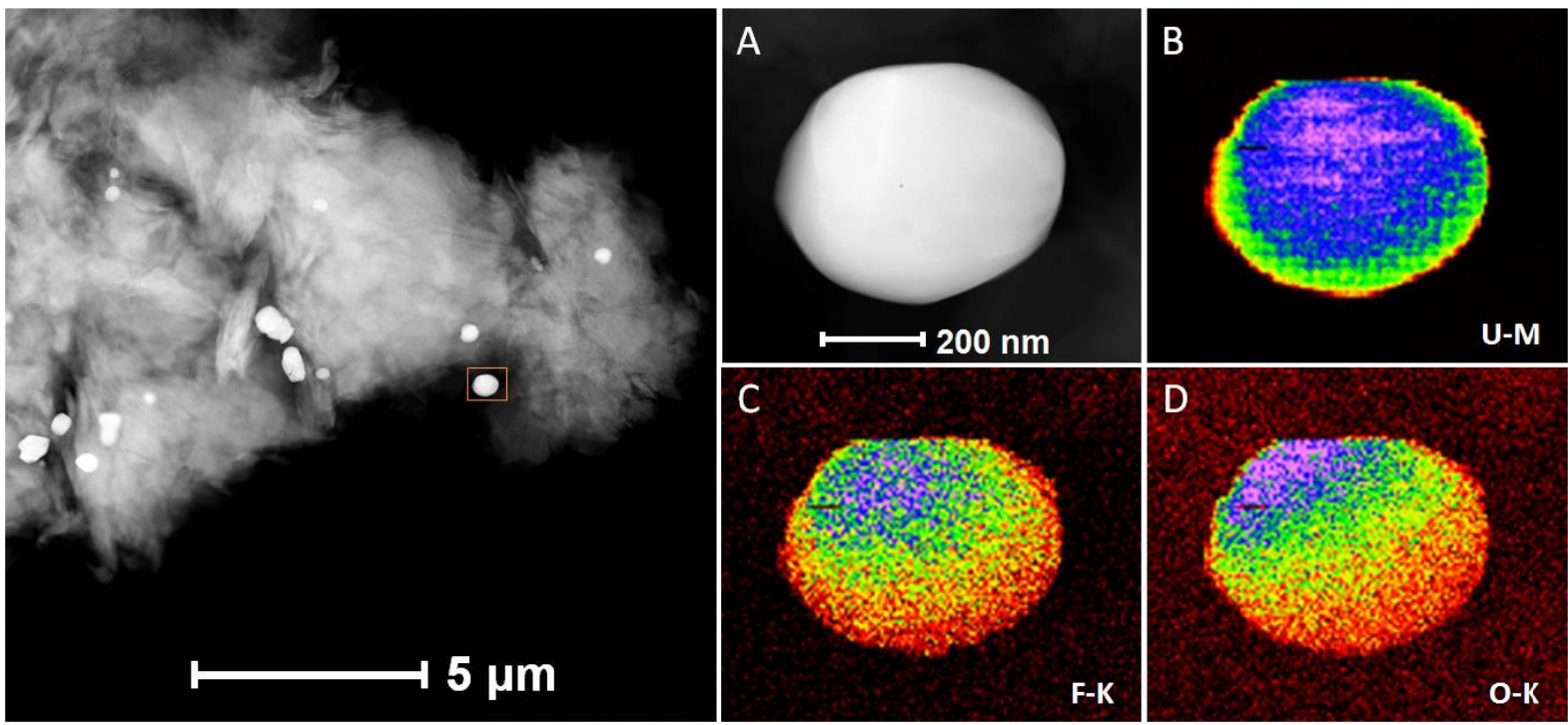

Fig 15: TEM image of uranium oxyfluoride particles on a $\mathrm{C}$ film (left)

and the electron image and $\mathrm{U}, \mathrm{F}$ and $\mathrm{O}$ elemental maps (right) of the particle marked by the red box in the TEM image

The transmission electron microscope (FEI Titan TEM) at LLNL is able to produce high resolution ( $\sim 4$ $\mathrm{nm}$ ) elemental maps of the distribution of uranium, fluorine and oxygen in a single uranium oxyfluoride particle. TEM uses the electrons that are transmitted through the sample, and so the particles had to be transferred from the graphite planchet to a carbon thin film, which is electron transparent. A $300 \mathrm{keV}$ electron beam with a probe size of approximately $1 \mathrm{~nm}$ was used to map the distribution of the main particle constituents in a sub-micron particle stored in argon since its preparation at IRMM (Figure 15). Even though the fluorine map seems to indicate that this element is not homogeneously distributed throughout the particle, the matching oxygen map and the electron image showing a 'bump' on that same side of the particle, indicate otherwise. These particles were very beam-sensitive as shown by the electron images taken before and after the analysis (Figure 16).

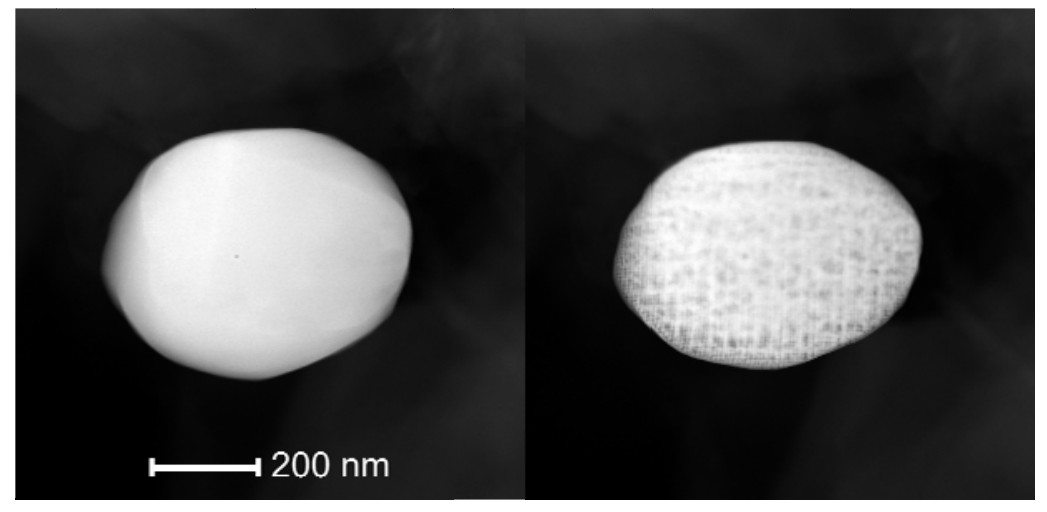

Fig 16: Electron images of the uranium oxyfluoride particle before (left) and after (right) TEM mapping showing obvious signs of electron beam damage 
A more quantitative approach is the generation of so-called EDX-profiles. For these measurements the TEM electron beam with a probe diameter of $\sim 1 \mathrm{~nm}$ is scanned on a line across the particle, and an EDX spectrum, corrected for variations in sample thickness, is collected for $4 \mathrm{~s}$ for every point along this line. The relative concentration of $\mathrm{U}, \mathrm{F}$ and $\mathrm{O}$ is presented in Figure 17. Although the fluorine concentration varied between particles from the same sample, its concentration did not exceed a few percent, and this lower than what we would expect from the structural formula of $\mathrm{UO}_{2} \mathrm{~F}_{2}$. The increase in fluorine and oxygen intensity near the edges of the particle is likely to be a measurement artifact. These data seem to indicate that fluorine is removed from the particle during this high-energy beam EDX analysis.

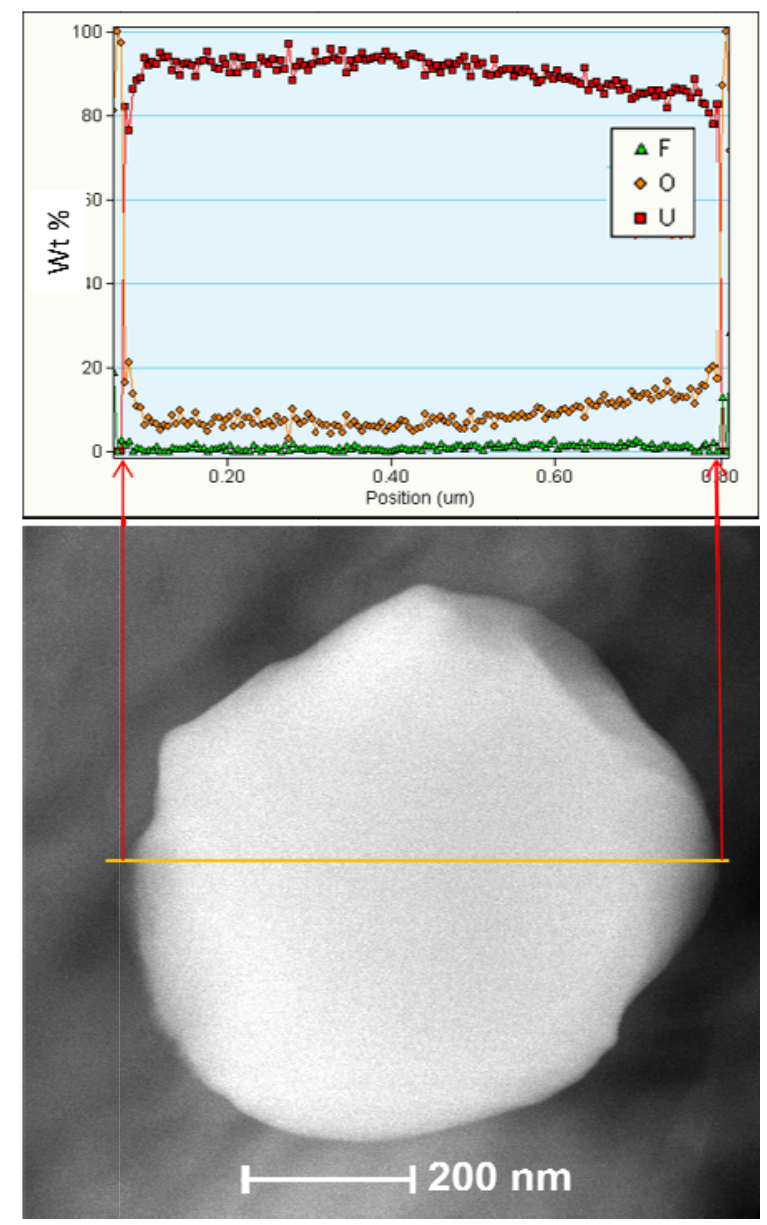

Fig 17: Energy-dispersive X-ray profiles collected by TEM showing the concentration of $F$, $U$ and $O$ in weight percent 


\section{Beyond elemental information: Micro-Raman Spectrometry(MRS)}

It's only recently that we started exploring the possibility of using the Raman spectrometry instrument at LLNL for the analysis of single particles. An optical microscope with a $100 \times$ objective was used to locate the particles on the graphite planchets and a laser beam with a spot size of $\sim 1 \mu \mathrm{m}$ was centered onto the particle to generate Raman scattering. A particle sample stored in argon since its preparation at IRMM was measured by the Raman system at LLNL using $514.5 \mathrm{~nm}$ (green) or $457.9 \mathrm{~nm}$ (blue) laser excitation produced by an $\mathrm{Ar}^{+}$laser, and a $632.8 \mathrm{~nm}$ (red) excitation from a HeNe laser. Comparison of the spectra taken at these three different wavelengths indicated that the use of the laser with the longest wavelength (red) and hence the least amount of energy per photon produced the most reproducible spectra. Because of the small size of the particles, the power had to be set sufficiently high, without depositing too much heat. Spectra recorded with the $632.8 \mathrm{~nm}$ laser at different power settings $(0.025 \mathrm{~mW}$ to $5.4 \mathrm{~mW}$ measured at the sample) indicated that the uranium oxyfluoride particles were extremely sensitive to the laser beam and only at power settings below $0.8 \mathrm{~mW}$ (step function) did the particles not transform to $\mathrm{U}_{3} \mathrm{O}_{8}$. For these spectra, a peak characteristic of hydrated $\mathrm{UO}_{2} \mathrm{~F}_{2}$ was observed at around $863 \mathrm{~cm}^{-1}$, in addition to a peak at $847 \mathrm{~cm}^{-1}$ and a broader feature around $753 \mathrm{~cm}^{-1}$ (Figure 18). The relative intensity of the peaks at $863 \mathrm{~cm}^{-1}$ and $847 \mathrm{~cm}^{-1}$ varied as the power of the laser was changed. The spectrum in Figure 19 shows the spectral pattern of $\mathrm{U}_{3} \mathrm{O}_{8}$ and was obtained after the laser power was increased above the threshold.

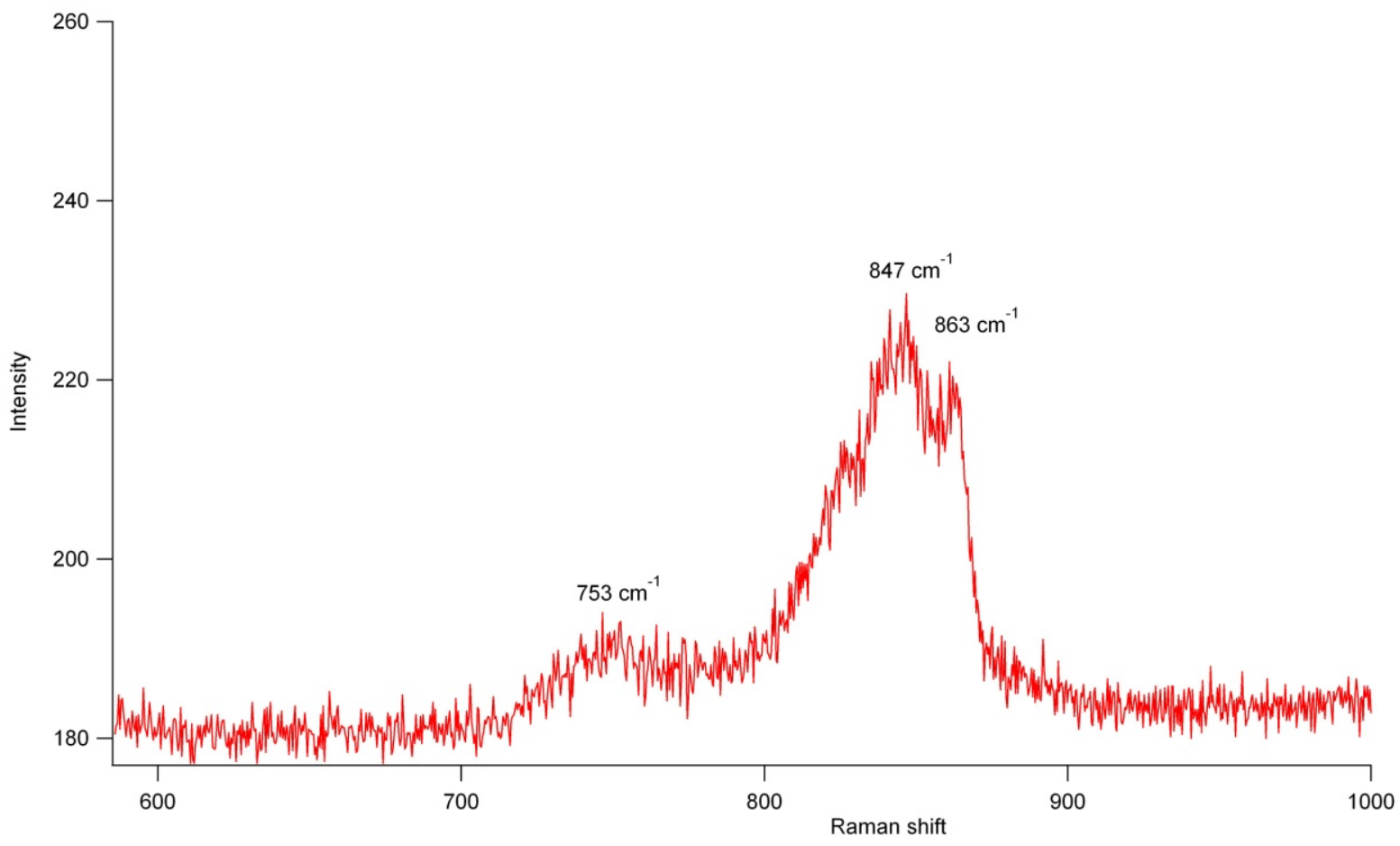

Fig 18: Typical micro-Raman spectrum of a uranium oxyfluoride particle obtained by $632.8 \mathrm{~nm}$ laser excitation at $0.23 \mathrm{~mW}$ 
The spectra of the uranium oxyfluoride particle samples were compared to those obtained from a $\mathrm{UO}_{2} \mathrm{~F}_{2}$ sample prepared from the hydrolysis of $\mathrm{UF}_{6}$ in water, instead of moist air. Large particles $(10-100 \mu \mathrm{m})$ from this crushed $\mathrm{UO}_{2} \mathrm{~F}_{2}$ material were dispersed onto a graphite planchet. These larger particles were less sensitive to the laser beam and the decomposition to $\mathrm{U}_{3} \mathrm{O}_{8}$ occurred at much higher power settings.

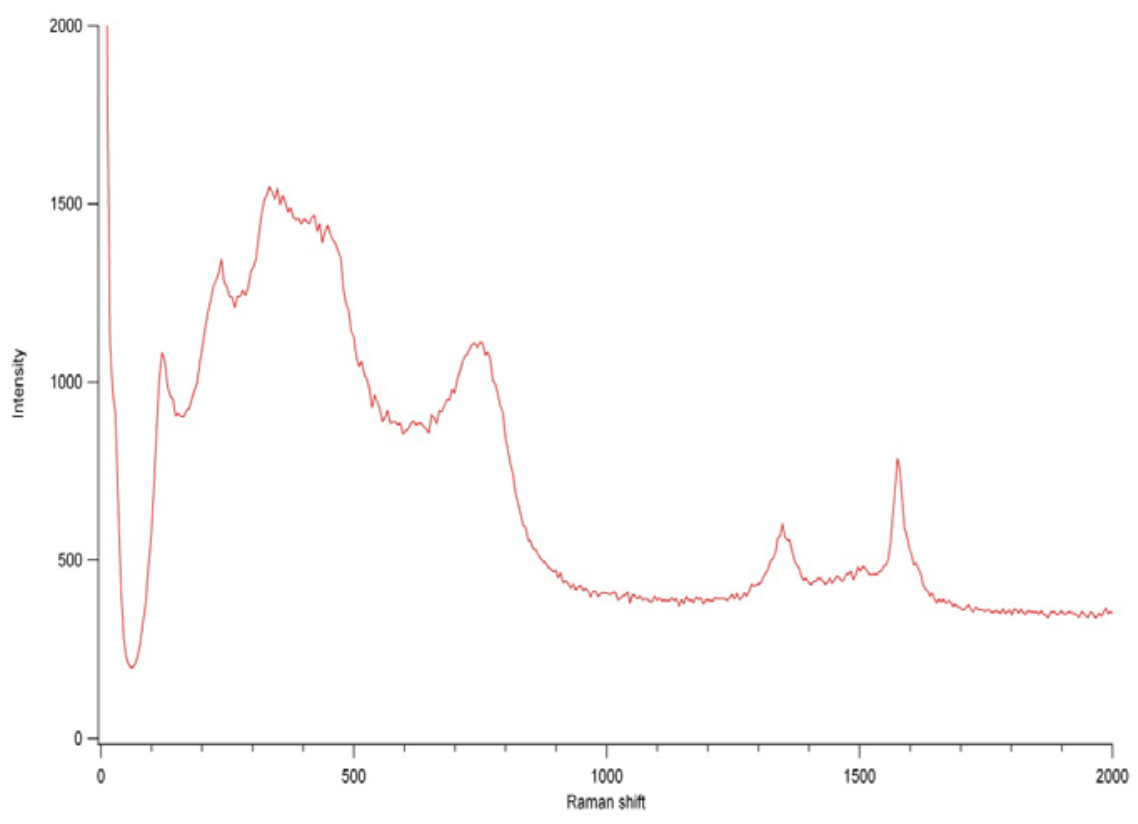

Fig 19: The exposure to high energy laser excitation, in this example $514 \mathrm{~nm}$ at $1 \mathrm{~mW}$, transformed the uranium oxyfluoride particle to $\mathrm{U}_{3} \mathrm{O}_{8}$ as shown in this Raman spectrum

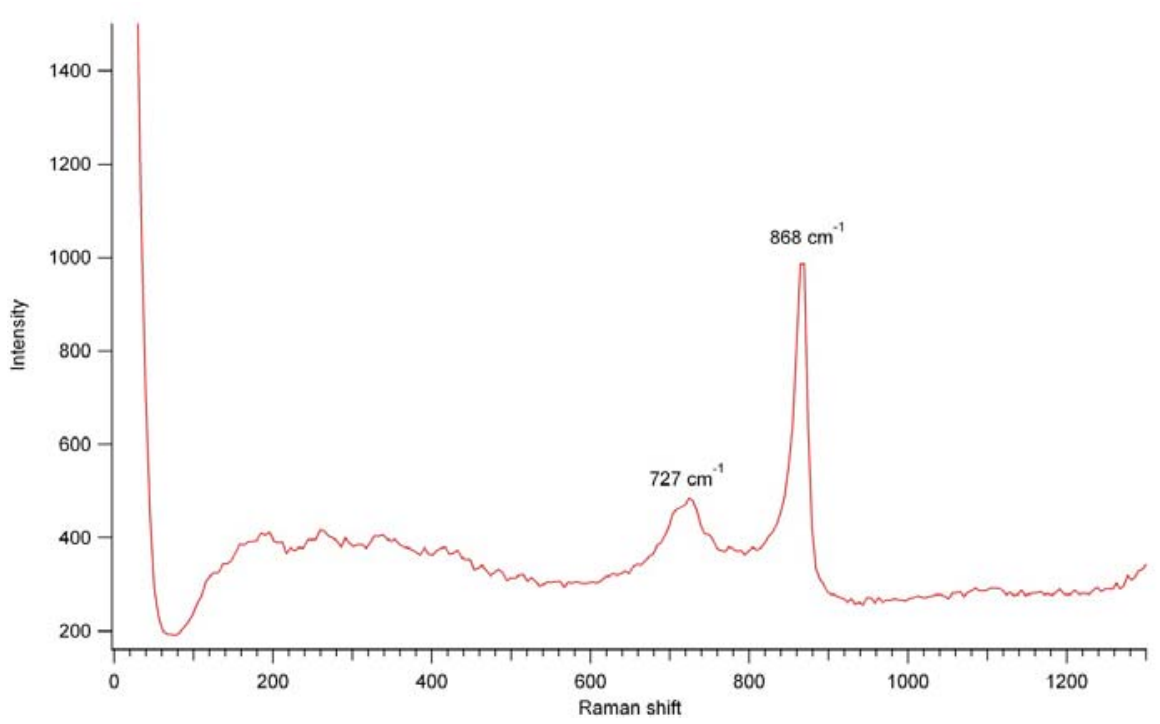

Fig 20: Micro-Raman spectrum of a uranium oxyfluoride particle formed from the hydrolysis of $\mathrm{UF}_{6}$ in water, as opposed to moist air. Similar to the particles prepared in moist air, the spectrum shows a peak around $868 \mathrm{~cm}^{-1}$, characteristic for $\mathrm{UO}_{2} \mathrm{~F}_{2}$, while the peak at $847 \mathrm{~cm}^{-1}$ was not observed for this compound. 
At reduced laser power, the peak characteristic of $\mathrm{UO}_{2} \mathrm{~F}_{2}$ was detected in the spectrum (Figure 20).

Because of the much larger particle size, the intensity of this peak was generally much higher than that of the uranium oxyfluoride particles prepared at IRMM. In contrast to the latter spectrum however, the peak at $847 \mathrm{~cm}^{-1}$ was not observed for this compound. Although these are only preliminary experiments, this observation seems to indicate that there is a significant difference in molecular structure between the particles formed from $\mathrm{UF}_{6}$ hydrolysis in water and those produced by a gas-phase condensation. Relative shifts in the Raman spectrum could be caused by different degrees of hydration, while the additional peak in the spectrum of the particles formed in moist air may be attributed to the co-existence of spectroscopically-distinct uranium phases in a single particle. 


\section{Conclusions \& Outlook}

After their preparation in January 2009, a set of fresh and aged uranium oxyfluoride particles has been analyzed at LLNL by a suite of micro-analytical techniques.

NanoSIMS analysis on single particles stored up to 7 months in dry air did not detect a significant decrease in the relative amount of fluorine. The exposure to high humidity however, caused a large variability in the $\mathrm{F}^{+} / \mathrm{U}^{+}$ratio, up to 2 orders of magnitude below that of the particles stored in dry air. In addition, SEM imaging revealed changes in particle morphology after exposure to high humidity.

The particles that were (partially) sputtered by NanoSIMS showed a rather porous morphology as demonstrated by SEM imaging. Although this porosity may have been introduced by the sputtering process, FIB cross-sectioning did reveal the presence of small voids in the center and at the edge of the particle. Because of their small size, the composition of these voids could not be determined. High spatial resolution TEM imaging and elemental mapping on the other hand, did not show clear evidence of fluorine inhomogeneities throughout the particle, although the particles were found to be very beamsensitive.

Through micro-Raman spectrometry we were able to complement the elemental and imaging data with information on the molecular structure of the particles. A peak characteristic of $\mathrm{UO}_{2} \mathrm{~F}_{2}$ was detected at $867 \mathrm{~cm}^{-1}$. The presence of other features in the Raman spectrum indicated that several uranium phases coexist in the particles produced from gas-phase $\mathrm{UF}_{6}$ hydrolysis.

In conclusion, NanoSIMS, SEM-EDX, FIB, TEM and MRS measurements demonstrated that each of these technique contributed to a detailed picture of the morphology, chemical composition and molecular structure of freshly-prepared uranium oxyfluoride particles. NanoSIMS measurements showed that particle ageing is a very slow process, as no significant changes were observed in the relative fluorine concentration after 7 months of storage in dry air. Storage in $76 \%$ on the other hand removed most of the fluorine within 3 months after preparation. The relative humidity for two of the four chambers was therefore changed to $30 \%$ and $40 \%$ to study the effect of moderate humidity levels on particle composition. The effect of UV-light on particle composition will also be investigated.

Because of the wide range of analytical techniques that were applied to these samples, including the measurements carried out at PNNL, and given the slow nature of the ageing process and the change in the experimental set up for particle storage (more moderate humidity conditions), we would need to prepare an additional set of uranium oxyfluoride particle samples at IRMM in order to finalize this study. At this point, we still have a total of 20 samples (graphite + sapphire) ageing in the environmental chambers, and 27 samples are stored in an argon atmosphere to preserve their initial composition.

A proposal for additional sample preparation at IRMM is included at the end of this text. For this set of particle samples, we would like to include samples that were prepared in a dry and moderate humidity atmosphere, in addition to those particle samples formed from hydrolysis in high humidity. For isotopic mixing studies, we would like to prepare a batch of particle samples produced from the consecutive hydrolysis of two different $\mathrm{UF}_{6}$ materials $(20 \%$ enriched $+\mathrm{LEU})$. 


\section{Acknowledgements}

This work has been performed under the auspices of the U.S. Department of Energy through a joint program between Lawrence Livermore National Laboratory (under contract DE-AC52-07NA27344) and the Pacific Northwest National Laboratory (under contract DE-AC05-76RL01830), and under the auspices of the European Commission, DG Joint Research Centre under Action Sheet 36.

The authors would like to acknowledge the following co-workers: Jonathan Crowhurst for the Raman spectrometry measurements, Nick Teslich for the SEM-FIB sample preparation and Zurong Dai for the TEM characterization, and Yetunde Aregbe, Elzbieta Stefaniak and Jan Truyens at IRMM for their help with the particle preparation. The particle samples prepared at IRMM were prepared expressly for the purpose of this study. 


\section{Attended conferences and publications March - November 2009}

- Kips, R., Kristo M. J, "Investigation of chemical changes in uranium oxyfluoride particles using secondary ion mass spectrometry," Journal of Radioanalytical and Nuclear Chemistry, presented at the conference for Methods and Applications of Radioanalytical Chemistry (MARC VIII), April 2009, Kailua-Kona, HI

- $\quad$ Kips, R., Kristo, M. J., Hutcheon, I. D., Amonette, J., Wang, Z., Johnson, T., Gerlach, D., Olsen, K. B., "Determination of the relative amount of fluorine in uranium oxyfluoride particles using secondary ion mass spectrometry and optical spectroscopy", Conference proceedings of the $50^{\text {th }}$ Annual Meeting of the Institute for Nuclear Materials Management (INMM), July 2009, Tucson, AZ

- Kips, R., Kristo, M. J., Hutcheon, I. D., Amonette, J., Wang, Z., Johnson, T., Gerlach, D., Olsen, K. B., Stefaniak E., "Measuring fluorine in uranium oxyfluoride particles using secondary ion mass spectrometry for nuclear forensics", to be presented at the Asia-Pacific Symposium on Radiochemistry (APSORC), November 2009, Napa, CA

- Presentation on uranium oxyfluoride particle work and lab tour at PNNL planned for 12/16/2009 


\section{Proposed sample preparation at IRMM}

Substrate type

- $\quad 3 / 8$ " diameter graphite planchets
o NanoSIMS
o Raman
o FIB
o SEM-EDX

- $\quad$ sapphire discs

o CLIFS, Raman (PNNL)

- 1 " diameter graphite planchets

o SIMS (PNNL)

- carbon thin films

o TEM

Number of samples

- $\quad 70$ x 3/8" diameter graphite planchets

- 40 x sapphire discs

- $5 \times 1$ × graphite planchets

- $\quad 10 \times$ C thin films

\section{$U F_{6}$ hydrolysis conditions}

- $\quad 2$ batches in $<15 \%$ rel. humidity air

- $\quad 3$ batches in $>70 \%$ rel. humidity air

- 1 batch in 45-50\% rel. humidity air

- 1 batch produced from the consecutive hydrolysis of 2 different $\mathrm{UF}_{6}$ materials (LEU $+20 \%$ enriched)

Sample preparation planning (2 weeks)

- 1 day of set up

- 6 days of sample preparation

- 2 days of sample characterization using SEM

- 1 day of shipment 